\title{
Cardiopulmonary effects of medetomidine or midazolam in combination with ketamine or tiletamine/zolazepam for the immobilisation of captive cheetahs (Acinonyx jubatus)
}

\author{
G F Stegmann ${ }^{\mathrm{a}^{*}}$ and $\mathrm{M}$ Jago ${ }^{\mathrm{b}}$
}

\begin{abstract}
Captive cheetah (Acinonyx jubatus) scheduled for either general health examination or dental surgery were immobilised with combinations of medetomidine-ketamine (K/DET, $n=19$ ), midazolam-ketamine (K/MID, $n=4)$ or medetomidine-tiletamine-zolazepam $(\mathrm{Z} / \mathrm{DET}, n=5)$. Induction time and arterial blood pressure was not statistically significantly $(P>0.05)$ different between treatment groups. Transient seizures were observed in the $\mathrm{K} / \mathrm{DET}$ treated animals during induction. Hypertension was present in all groups during anaesthesia with mean $( \pm \mathrm{SD})$ systolic pressure of $30.7 \pm 5.0 \mathrm{kPa}$ for the K/DET group, $27.7 \pm$ $2.7 \mathrm{kPa}$ for the K/MID group, and $33.1 \pm 4.6 \mathrm{kPa}$ for the Z/DET group. Heart rate was statistically significantly $(P<0.05)$ lower in the K/DET group $(69 \pm 13.2$ beats/min $)$ compared to the K/MID group ( $97 \pm 22.6$ beats $/ \mathrm{min}$ ), and ventilation rate was statistically significantly $(P<0.05)$ lower in the K/MID group $(15 \pm 0.0$ breaths/min) compared with the K/DET group $(21 \pm 4.6)$. A metabolic acidosis and hypoxia were observed during anaesthesia when breathing air. Oxygen $\left(\mathrm{O}_{2}\right)$ administration resulted in a statistically significant $(P<0.05)$ increase in the arterial partial pressure of carbon dioxide (hypercapnoea), arterial partial pressure of $\mathrm{O}_{2}$, and \% oxyhaemoglobin saturation.
\end{abstract}

Key words: Acinonyx jubatus, anaesthesia, cheetah, hypertension, hypoxia, immobilisation, ketamine, midazolam, medetomidine, seizures, tiletamine, zolazepam.

Stegmann G F, Jago M Cardiopulmonary effects of medetomidine or midazolam in combination with ketamine or tiletamine/zolazepam for the immobilisation of captive cheetahs (Acinonyx jubatus). Journal of the South African Veterinary Association (2006) 77(4): 205-209 (En.). Department of Companion Animal Clinical Studies, Faculty of Veterinary Science, University of Pretoria, Private Bag X04, Onderstepoort, 0110 South Africa.

\section{INTRODUCTION}

Reports on the suitability of anaesthetic drugs for immobilisation and anaesthesia in cheetah (Acinonyx jubatus) are limited. Combinations of xylazine-ketamine $\mathrm{e}^{12,15}$ or tiletamine-zolazepam ${ }^{12,15}$, and phencyclidine-acepromazine ${ }^{9}$ were reported previously. Deem and co-workers ${ }^{2}$ reported on the use of tiletamine/zolazepam in combination with medetomidine for immobilisation of cheetahs and observed systemic arterial hypertension during anaesthesia. Hypertension was also reported in other carnivore species after the use of medetomidine $e^{11,19}$. Hypertension is ascribed to be the result of increased peripheral resistance induced by the use of $\alpha_{2}$-adrenergic agonists such as medetomidine or xylazine ${ }^{20}$. In wolves the combination of medetomidine and apepartment of Companion Animal Clinical Studies, Faculty of Veterinary Science, University of Pretoria, Private Bag X04, Onderstepoort, 0110 South Africa.

${ }^{\mathrm{b} T h e}$ AfriCat Foundation, PO Box 1889, Otjiwarongo, Namibia.

${ }^{*}$ Author for correspondence.

E-mail: frik.stegmann@ up.ac.za

Received: July 2006. Accepted: November 2006. ketamine resulted in prolonged hypertension $^{11}$. In dogs renal failure has also been reported as a cause of hypertension ${ }^{4}$ and in humans high blood pressure may aggravate pre-existing chronic renal disease ${ }^{1}$. As kidney disease is known to occur in cheetahs ${ }^{16}$ and $\alpha_{2}$-adrenergic agonists are known to decrease renal perfusion and increase blood pressure ${ }^{19}$, consideration should be given to the possibility that these drugs may contribute to increased renal morbidity in animals with pre-existing renal disease.

The purpose of this investigation was to examine the cardiopulmonary effects of ketamine/medetomidine (K/DET), tiletamine/zolazepam/medetomidine (Z/DET) and ketamine/midazolam (K/MID) used for immobilisation in captive cheetahs.

\section{MATERIALS AND METHODS}

Twenty-eight cheetahs respectively kept either at the De Wildt Cheetah Centre (Pretoria, South Africa) or AfriCat (Otjiwarongo, Namibia) were immobilised for either a general medical exami- nation (AfriCat) or dental surgery (De Wildt). Cheetahs were fasted overnight and water was withheld from the morning prior to immobilisation. Cheetahs were either herded individually into either a crush (De Wildt) and then injected intramuscularly with a pole syringe (De Wildt) or into a small camp (AfriCat) and then darted using a rifle and projectile syringe (Dan-Inject, Sweden). The body weight of the animals was initially estimated for the induction dose to be administered and then accurately weighed after immobilisation for exact dose calculations. Induction time was taken as the time from drug administration until the animals could be handled without reflex movement in response to handling. After immobilisation the anaesthetic depth of the cheetah was monitored by observing response to handling, skeletal muscle tone, heart rate, ventilation rate, mucous membrane colour and rectal temperature at 5-minute intervals. Ambient and rectal temperatures were monitored at 5-minute intervals with the temperature probe from the monitor during the period of immobilisation. When the rectal temperature increased to $>39.5^{\circ} \mathrm{C}$ the hair coat was sprayed with water, ice packs applied and a electric fan turned on until the temperature decreased to $38^{\circ} \mathrm{C}$. Following recovery from immobilisation, all cheetahs were observed intermittently for a further 24 hours. A full autopsy was conducted on the animal that died.

The cheetahs were immobilised with either K/DET $(n=19)$, or Z/DET $(n=5)$, or M/DET $(n=4)$. At De Wildt the total dose for the K/DET combination varied between 0.2 and $0.4 \mathrm{mg}$ for medetomidine (Domitor, Pfizer) and for ketamine hydrochloride (Anaket, Bayer) varied between 100 and $400 \mathrm{mg}$. For the Z/DET combination the total dose for ketamine hydrochloride was $400 \mathrm{mg}$ and for midazolam (Dormicum, Roche) $15 \mathrm{mg}$. At AfriCat the total dose for the K/DET combination varied between 0.5 and $1.8 \mathrm{mg}$ for medetomidine and 120 and $180 \mathrm{mg}$ for ketamine. The total dose for tiletamine-zolazepam (Zoletil $^{\circledR}$, Virbac) varied between 60 and 
$180 \mathrm{mg}$. In 3 instances additional ketamine or tiletamine-zolazepam were administered to obtain complete immobilisation (no response to handling) in the cheetah at AfriCat. The choice of drug combination was made by the author without prior knowledge of the individual animal to be immobilised or the procedure to be performed. For dental surgery, anaesthesia was maintained with isoflurane in oxygen. The trachea was intubated and connected to a circle breathing circuit with carbon dioxide absorption with the vaporiser setting at $0.5-1 \%$. Fresh gas flow rate was set at $10 \mathrm{~m} / / \mathrm{kg} / \mathrm{min}$. If cyanosis of the oral mucous membrane was observed when breathing air, the trachea was intubated and the cheetah connected to the anaesthetic machine to breath oxygen. During immobilisation blood volume was maintained with the intravenous administration of a balanced electrolyte solution (Intramed Ringer Lactate Solution) after the placement of a $18 \mathrm{G}$ catheter (Jelco, Johnson \& Johnson) in the cephalic vein, and administered at a rate of $10 \mathrm{~m} / \mathrm{kg} / \mathrm{h}$.

At the end of surgery atipamizole (Antisedan, Pfizer) was administered to antagonise medetomidine in animals where it was used for immobilisation. The dose administered was 0.5 of the volume of medetomidine administered. For recovery, the cheetahs at DeWildt were individually placed in a small pen. At AfriCat the animals were individually placed in crates until recovered (standing without signs of sedation) and thereafter returned to their respective camps.

Arterial blood pressure was measured using a multifunction patient monitor (Critikon Dinamap Plus Vital Signs Monitor). The arterial catheter (20G Jelco, Johnson \& Johnson) was connected to a calibrated pressure transducer for measurement of systolic pressure (SYS), diastolic pressure (DIA), mean arterial pressure (MAP) and heart rate (HR). Upon failure to catheterise either the medial saphenous or the femoral artery, an infant-size blood pressure cuff (for $10-19 \mathrm{~cm}$ limb circumference) was placed over either the distal humerus or distal femur.

Blood-gas analysis of arterial blood was performed with a blood-gas analyser (Osmetech Opti CCA, Roswell Georgia). Arterial blood was collected anaerobically in $2 \mathrm{~m} \ell$ heparinised plastic syringes approximately $15 \mathrm{~min}$ after immobilisation. In 3 animals a 2 nd sample was taken at the end of dental surgery (sample interval varied between 15 and $30 \mathrm{~min}$ ). Processing was performed immediately after blood collection. Results were corrected for body temperature.

\section{Data analysis}

Data were analysed for normality of distribution and reported as the mean $( \pm S D)$. The mean values for non-invasive and invasive blood pressure measurements were calculated separately. A general linear model multivariate procedure for multiple dependent variables was used for comparison between treatments. When significant differences were found, Bonferroni's multiple comparison post hoc test was applied to identify significantly different treatment groups. A 95\% confidence interval for significance of difference was accepted $(P<0.05)$. Owing to the variation in the number of observations over time (length of procedure), only the 1st observation from each variable was used for comparison between treatment groups.

For comparison of the arterial blood-gas variables, and the invasive and non-invasive blood pressure measurements an independent-samples T-test was used. When a 2nd blood-gas sample was collected from the same animal it was only used for comparison of values before and after oxygen administration and not included for calculation of mean values. Data were analysed using a personal computer with SPSS for Windows Ver. 13 software program (SPSS Inc., Chicago, Illinois). The Animal Use and Care Committee of the University of Pretoria approved of this investigation (V064/05).

\section{RESULTS}

The mean $( \pm S D)$ body weight of the cheetahs was $36.8( \pm 5.2) \mathrm{kg}$ with the range between 26 and $50 \mathrm{~kg}$. The mean induction time for the K/DET group $(n=$ 19) was $9.2( \pm 3.4)$ minutes, $11.3( \pm 1.0)$ min for the K/MID group $(n=4)$ and 16.8 $( \pm 18.1) \mathrm{min}$ for the Z/DET group $(n=5)$, and the differences were not statistically significant $(P=0.30)$. The mean dose for medetomidine was $0.027 \mathrm{mg} / \mathrm{kg}$, for midazolam $0.4 \mathrm{mg} / \mathrm{kg}$, ketamine $6.9 \mathrm{mg} / \mathrm{kg}$, and tiletamine-zolazepam $2.9 \mathrm{mg} / \mathrm{kg}$. Transient seizures were observed in 3 cheetahs immobilised with a high dose of ketamine ( $400 \mathrm{mg}$ ) combined with medetomidine, but not when combined with midazolam.

The mean $( \pm S D)$ values for ventilation rate, cardiovascular variables, and arterial blood-gas variables are reported in Tables 1 and 2, respectively. Distribution of values was not normal for HR in the Z/DET group (median HR 66). For comparison between treatments, a statistical significant difference $(P=0.034)$ was found for HR between the K/DET (mean $69 \pm 13.2$ ) and K/MID (mean $97 \pm 22.6$ ). Differences for HR between K/DET and Z/DET (mean $83 \pm 17.3$ ), and K/MID and
Z/DET were not statistically significant $(P=0.66, P=0.17$, respectively). Differences for SYS, DIA and MAP between treatments were not statistically significant $(P>0.05)$. Differences in blood pressure between invasive and non-invasive measurements (Z/DET group) were statistically significant for SYS $(P=0.03)$, DIA $(P=0.03)$ and $\operatorname{MAP}(P=0.04$, Table 1$)$. The failure rate to catheterise the medial saphenous artery was high, and resulted in placing the catheter in the femoral artery. The failure rate to obtain a blood pressure reading with the cuff was also high.

For ventilation rate a statistical significant difference $(P=0.001)$ was found between K/DET (mean $21 \pm 4.6$ ) and $\mathrm{K} / \mathrm{MID}$ (mean $15 \pm 0$ ). The difference between Z/DET (mean $24.0 \pm 7.5$ ) and K/DET or K/MID was not significant $(P=$ 0.92 and $P=0.22$, respectively). For arterial blood-gas variables: $\mathrm{pH}$, partial pressure of carbon dioxide $\left(\mathrm{PCO}_{2}\right)$, partial pressure of oxygen $\left(\mathrm{PO}_{2}\right)$, base excess (BE), plasma bicarbonate $\left(\mathrm{HCO}_{3}\right)$, and oxyhaemoglobin saturation $\left(\mathrm{O}_{2} \mathrm{SAT}\right)$ the differences were not statistically significant $(P>0.05)$ between the K/DET and Z/DET groups when breathing air (Table 2). A metabolic acidosis was present in most animals with a $\mathrm{pH}<7.40$ associated with decreased values for $\mathrm{BE}$ and $\mathrm{HCO}_{3}$. In the $\mathrm{K} / \mathrm{DET}$ group, administration of oxygen resulted in statistical significant change in the $\mathrm{PO}_{2}(P<0.03), \mathrm{PCO}_{2}(P<0.02), \mathrm{O}_{2} \mathrm{SAT}$ $(P<0.0001)$ and $\mathrm{pH}(P<0.004)$. The mean rectal temperature was $38.8{ }^{\circ} \mathrm{C}( \pm 0.9)$. Environmental temperatures at AfriCat were at maximum $26^{\circ} \mathrm{C}$. High temperatures were experienced at De Wildt $\left(38^{\circ} \mathrm{C}\right)$ and part of the scheduled surgery was cancelled due to the danger of heat stroke.

Recovery was uneventful at AfriCat. At De Wildt, 3 animals from the K/DET group still appeared sedated $24 \mathrm{~h}$ after administration of atipamizole. One cheetah from K/MID group died $36 \mathrm{~h}$ after anaesthesia. Necropsy examination of this cheetah indicated foreign body aspiration and asphyxia from a commercial dog food meal.

\section{DISCUSSION}

The high failure rate to measure arterial blood pressure in the cheetah resulted in the unequal distribution of treatment numbers. It is possible that peripheral vasoconstriction caused by medetomidine $\left(\alpha_{2}\right.$-adrenergic agonist) may have contributed towards this failure. The low numbers in the Z/DET $(n=5)$ and K/MID $(n=4)$ groups as opposed to the K/DET $(n=19)$ group may have adversely influenced the power of statistical analysis obtained in this investigation. 
Table 1: Mean \pm SD values for heart rate, invasive and non-invasive arterial blood pressures in anaesthetised cheetahs.

\begin{tabular}{|c|c|c|c|c|c|}
\hline Anaesthetic & $\begin{array}{l}\text { Vent rate } \\
\text { (Br/min) }\end{array}$ & $\begin{array}{l}\text { Heart rate } \\
(\mathrm{Bt} / \mathrm{min})\end{array}$ & $\begin{array}{l}\text { Systolic BP } \\
\quad(\mathrm{kPa})\end{array}$ & $\begin{array}{l}\text { Diastolic BP } \\
\quad(\mathrm{kPa})\end{array}$ & $\begin{array}{l}\text { MAP } \\
(\mathrm{kPa})\end{array}$ \\
\hline \multirow[t]{19}{*}{$\mathrm{K} / \mathrm{DET}(n=19)$} & $24 \pm 3.3$ & $48 \pm 4.2$ & $22.2 \pm 2.2$ & $13.6 \pm 0.13$ & $16.6 \pm 1.8$ \\
\hline & $20 \pm 1.6$ & $72 \pm 6.9$ & $21.4 \pm 2.0$ & $12.4 \pm 2.2$ & $17.0 \pm 2.0$ \\
\hline & $24 \pm 1.4$ & $91 \pm 20.5$ & $23.8 \pm 5.1$ & $15.8 \pm 1.9$ & $18.5 \pm 5.9$ \\
\hline & $24 \pm 1.6$ & $63 \pm 10.4$ & $29.8 \pm 1.2$ & $21.9 \pm 4.9$ & $24.1 \pm 3.6$ \\
\hline & $24 \pm 3.3$ & $63 \pm 12.7$ & $28.6 \pm 4.2$ & $19.2 \pm 3.8$ & $23.1 \pm 3.7$ \\
\hline & $22 \pm 1.6$ & $77 \pm 4.9$ & $31.4 \pm 0.01$ & $22.1 \pm 2.4$ & $24.9 \pm 2.1$ \\
\hline & $20 \pm 2.2$ & 64 (SV) & $34.4 \pm 0.01$ & $22.3 \pm 0.01$ & $25.4 \pm 0.1$ \\
\hline & $23 \pm 2.2$ & $70 \pm 20.5$ & $34.8 \pm 2.5$ & $23.3 \pm 0.4$ & $26.2 \pm 0.7$ \\
\hline & $20 \pm 2.9$ & $49 \pm 8.5$ & $36.2 \pm 0.1$ & $21.8 \pm 0.4$ & $25.7 \pm 0.4$ \\
\hline & $11 \pm 1.4$ & $52 \pm 4.9$ & $27.9 \pm 1.2$ & $18.1 \pm 0.2$ & $20.7 \pm 0.1$ \\
\hline & $12 \pm 1.4$ & 92 (SV) & 37.1 (SV) & 24.1 (SV) & 27.4 (SV) \\
\hline & $20 \pm 1.6$ & $68 \pm 2.8$ & $28.6 \pm 0.4$ & $21.0 \pm 0.3$ & $23.3 \pm 0.3$ \\
\hline & $12 \pm 0.8$ & $77 \pm 0.1$ & $38.7 \pm 0.9$ & $23.8 \pm 0.9$ & $28.2 \pm 0.7$ \\
\hline & $20 \pm 2.2$ & $65 \pm 1.4$ & $34.4 \pm 0.1$ & $22.3 \pm 0.4$ & $25.4 \pm 0.1$ \\
\hline & $26 \pm 2.8$ & $70 \pm 20.5$ & $34.8 \pm 2.5$ & $23.3 \pm 0.4$ & $26.2 \pm 0.7$ \\
\hline & $24 \pm 4.6$ & $51 \pm 1.4$ & $27.0 \pm 4.0$ & $18.6 \pm 13.2$ & $21.1 \pm 0.1$ \\
\hline & $28 \pm 4.0$ & $66 \pm 0.7$ & $34.7 \pm 0.1$ & $22.7 \pm 0.9$ & $26.1 \pm 0.5$ \\
\hline & $22 \pm 2.6$ & $92 \pm 6.9$ & $29.9 \pm 0.4$ & $17.3 \pm 0.01$ & $24.3 \pm 0.3$ \\
\hline & $24 \pm 1.8$ & $77 \pm 6.6$ & $26.6 \pm 3.8$ & $18.8 \pm 3.1$ & $21.8 \pm 0.6$ \\
\hline Group mean & $21 \pm 4.6^{a}$ & $69 \pm 13.2^{b}$ & $30.7 \pm 5.0$ & $20.1 \pm 3.4$ & $23.5 \pm 3.3$ \\
\hline \multirow[t]{4}{*}{$\mathrm{K} / \mathrm{MID}(n=4)$} & $15 \pm 0.0$ & $121 \pm 1.8$ & $29.7 \pm 0.6$ & $16.4 \pm 20.5$ & $20.9 \pm 3.7$ \\
\hline & $15 \pm 0.0$ & $104 \pm 4.0$ & $26.9 \pm 5.0$ & $18.6 \pm 55.6$ & $23.1 \pm 5.6$ \\
\hline & $15 \pm 0.0$ & $67 \pm 2.3$ & $30.6 \pm 1.9$ & $25.9 \pm 3.3$ & $27.0 \pm 2.1$ \\
\hline & $15 \pm 0.0$ & $97 \pm 19.5$ & $23.7 \pm 9.7$ & $19.3 \pm 4.0$ & $22.6 \pm 2.8$ \\
\hline Group mean & $15 \pm 0.0^{\mathrm{a}^{\mathrm{a}}}$ & $97 \pm 22.6^{b^{\prime}}$ & $27.7 \pm 2.7$ & $19.3 \pm 4.5$ & $22.9 \pm 3.5$ \\
\hline \multirow[t]{5}{*}{ Z/Det $(n=5)$} & $19 \pm 3.4$ & $63 \pm 1.4$ & $27.1 \pm 0.5$ & $15.8 \pm 0.01$ & $19.8 \pm 0.4$ \\
\hline & $22 \pm 2.2$ & $92(\mathrm{SV})$ & 37.1 (SV) & $24.1(\mathrm{SV})$ & 27.4 (SV) \\
\hline & $14 \pm 1.4$ & 66 (SV) & $28.6 \pm 0.4$ & $21.0 \pm 0.3$ & $23.3 \pm 0.3$ \\
\hline & $24 \pm 2.8$ & 77 (SV) & $38.7 \pm 0.9$ & $23.8 \pm 0.9$ & $28.2 \pm 0.7$ \\
\hline & $36 \pm 1.6$ & 64 (SV) & 33.9 (SV) & $23.9 \pm S V$ & 26.3 (SV) \\
\hline Group mean & - & - & $33.1 \pm 4.6^{\mathrm{C}}$ & $21.7 \pm 3.2^{d}$ & $25.0 \pm 3.1$ \\
\hline \multirow[t]{5}{*}{ Z/DET $(n=5)$} & $19 \pm 3.6$ & 117 (SV) & $18.2(S V)$ & $8.8(S V)$ & $12.1(S V)$ \\
\hline & $14 \pm 1.6$ & 80 (SV) & 30.6 (SV) & $21.3(S V)$ & 24.2 (SV) \\
\hline & $36 \pm 1.4$ & 108 (SV) & 25.4 (SV) & 13.2 (SV) & 18.2 (SV) \\
\hline & $24 \pm 1.6$ & 80 (SV) & 20.3 (SV) & $12.4(S V)$ & 14.8 (SV) \\
\hline & $28 \pm 1.6$ & 78 (SV) & 28.9 (SV) & $17.2(S V)$ & 22.1 (SV) \\
\hline Group mean & $24 \pm 7.5$ & $83 \pm 17.3$ & $24.7 \pm 4.8^{c^{\prime}}$ & $14.5 \pm 4.3^{\mathrm{d}^{\prime}}$ & $18.2 \pm 4.5^{\mathrm{e}^{\mathrm{e}}}$ \\
\hline
\end{tabular}

$\mathrm{K}=$ ketamine DET = medetomidine; $\mathrm{MID}=$ midazolam; $\mathrm{Z}=$ Zoletil; Vent rate = ventilation rate, $\mathrm{Br}=$ breaths $/ \mathrm{min} ; \mathrm{Bt} / \mathrm{min}=\mathrm{beats} / \mathrm{min} ; \mathrm{BP}=\mathrm{blood}$ pressure; $\mathrm{MAP}=\mathrm{mean}$ arterial blood pressure; SV = single value; Italics indicate non-invasive blood pressures; ${ }^{\mathrm{a}-\mathrm{a}} \mathrm{a}, \mathrm{b}-\mathrm{b}^{\prime}, \mathrm{c}-\mathrm{c}^{\prime}, \mathrm{d}-\mathrm{d}$ ', e-e' $=$ statistically significant difference $(P<0.05)$.

The use of either ketamine or tiletamine-zolazepam combined with medetomidine or the combination of ketamine and midazolam had no statistical significant effect $(P<0.05)$ on induction time although a somewhat longer induction time was observed with the Z/DET (16.8 min ) combination.

Induction time is of clinical relevance as it should be kept as short as possible as increased locomotion during induction could increase body temperature in hot ambient temperatures. The induction time observed by Deem et al. ${ }^{2}$ of $4.3 \pm$ 2 min obtained after tiletamine-zolazepam $(1.5 \mathrm{mg} / \mathrm{kg})$ and detomidine $(0.03 \mathrm{mg} / \mathrm{kg})$ administration was much shorter than the induction time for the Z/DET group in this investigation although higher doses were used in this investigation. No particular reason for this could be found as the end-point for induction time appeared to be the same. The amount of excitation present in the animal at the time of drug administration is the only factor that may delay induction, and is a possible explanation for the differences in induction times.

The seizures observed in the cheetah induced with a high dose of ketamine $(10 \mathrm{mg} / \mathrm{kg})$ have not been reported previously. A dose of $10 \mathrm{mg} / \mathrm{kg}$ ketamine in combination with xylazine $(1 \mathrm{mg} / \mathrm{kg})$ was recommended by McKenzie and Burroughs ${ }^{15}$. Seizures may occur after ketamine administration in $\operatorname{dogs}^{3}$ but appear to be benign as no adverse effects have been reported. Medetomidine may decrease the threshold for seizures ${ }^{13}$ and could facilitate the onset of seizures in the presence of ketamine. Midazolam increases the seizure threshold in humans ${ }^{18}$ and is probably the reason why seizures were not observed with the K/MID group. Arterial blood pressure was not significantly different $(P<0.05)$ between the anaesthetic combinations (Table 1). Possible hypertension occurred in all anaesthetic combinations (treatment groups). The blood pressure of conscious cheetahs is not known and it is therefore not possible to objectively interpret the pressures observed during anaesthesia. Hypertension in dogs is defined as systolic/diastolic pressure $>23.9 / 13.3 \mathrm{kPa}(180 / 100 \mathrm{mmHg})$ though breed differences occur ${ }^{14}$. The MAP of $25.0 \pm 3.1 \mathrm{kPa}$ recorded with Z/DET was somewhat less compared with the $28.9 \mathrm{kPa}$ recorded by Deem et al. ${ }^{2}$. The pressure obtained with K/MID (22.9 \pm $3.5 \mathrm{kPa})$ compared similar with K/DET $(23.5 \pm 3.3 \mathrm{kPa})$ in this investigation. It was accepted that the high blood pressure 
Table 2: Individual and mean \pm SD arterial blood-gas values from anaesthetised cheetahs breathing air or oxygen.

\begin{tabular}{|c|c|c|c|c|c|c|c|}
\hline Anaesthetic & pH units & $\begin{array}{l}\mathrm{PCO}_{2} \\
(\mathrm{kPa})\end{array}$ & $\begin{array}{l}\mathrm{PO}_{2} \\
(\mathrm{kPa})\end{array}$ & $\begin{array}{c}\text { BEI } \\
(\mathrm{mmol} / \mathrm{l})\end{array}$ & $\begin{array}{c}\mathrm{HCO}_{3} \\
(\mathrm{mmol} / \mathrm{l})\end{array}$ & $\begin{array}{c}\mathrm{O}_{2} \mathrm{SAT} \\
(\%)\end{array}$ & $\begin{array}{l}\text { Temp } \\
\left({ }^{\circ} \mathrm{C}\right)\end{array}$ \\
\hline \multirow{5}{*}{$\begin{array}{l}\text { Zoletil/Medet } \\
\text { + air }\end{array}$} & 7.22 & 6.1 & 9.2 & -7.1 & 19.8 & 82 & 39.5 \\
\hline & 7.35 & 4.5 & 10.1 & -6.3 & 18.1 & 92 & 37.8 \\
\hline & 7.42 & 3.7 & 7.3 & -5.3 & 18.0 & 84 & 37.8 \\
\hline & 7.41 & 4.1 & 9.2 & -3.9 & 19 & 90 & 38.0 \\
\hline & 7.29 & 3.2 & 8.2 & -12.9 & 11.4 & 86 & 39.3 \\
\hline Group mean & $7.34 \pm 0.08$ & $4.3 \pm 1.1$ & $8.8 \pm 1.1$ & $-7.1 \pm 3.4$ & $17.3 \pm 3.4$ & $90.0 \pm 2.6$ & \\
\hline \multirow{7}{*}{$\begin{array}{l}\text { Ket/Medet } \\
\text { +air }\end{array}$} & 7.36 & 4.3 & 10.1 & -6.4 & 17.5 & 92 & 38.0 \\
\hline & 7.33 & 4.0 & 11.2 & -8.6 & 14.9 & 91 & 40.0 \\
\hline & 7.36 & 4.0 & 9.4 & -7.5 & 16.2 & 90 & 38.0 \\
\hline & 7.38 & 4.0 & 10.2 & -6.3 & 16.8 & 91 & 39.0 \\
\hline & 7.38 & 4.1 & 8.9 & -5.6 & 17.3 & 87 & 39.0 \\
\hline & 7.44 & 3.7 & 10.6 & -3.9 & 18 & 93 & 39.0 \\
\hline & $7.42^{1}$ & 4.1 & 8.0 & -4.1 & 19.4 & 86 & 37.5 \\
\hline Group mean & $7.38 \pm 0.04^{\mathrm{a}}$ & $4.0 \pm 0.2^{b}$ & $9.8 \pm 1.1^{\mathrm{c}}$ & $-6.1 \pm 1.7$ & $17.2 \pm 1.4$ & $87.0 \pm 4.1^{d}$ & \\
\hline Ket/Medet & $7.27^{2}$ & 6.8 & 36.0 & -4.1 & 22.9 & 100 & 37.4 \\
\hline \multirow{6}{*}{ + oxygen } & $7.21^{1}$ & 6.8 & 28.6 & -7.9 & 19.7 & 99 & 39.6 \\
\hline & $7.20^{2}$ & 6.8 & 32.5 & -8.3 & 19.4 & 100 & 39.2 \\
\hline & 7.35 & 7.3 & 13.0 & 2.7 & 29.6 & 97 & 38.1 \\
\hline & $7.25^{1}$ & 6.9 & 16.2 & -5.4 & 22.0 & 98 & 39.4 \\
\hline & $7.37^{2}$ & 4.7 & 5.9 & -5.1 & 19.4 & 64 & 39.1 \\
\hline & 7.23 & 2.3 & 12.2 & -17.8 & 7.1 & 78 & 40.5 \\
\hline Group mean ${ }^{e}$ & $7.26 \pm 0.05^{\mathrm{a}^{\prime}}$ & $6.01 \pm 2.1^{\mathrm{b}^{\prime}}$ & $21.2 \pm 10.6^{c^{\prime}}$ & $-6.5 \pm 7.4$ & $20.3 \pm 8.2$ & $94.4 \pm 9.2^{d^{\prime}}$ & $38.8 \pm 0.9$ \\
\hline
\end{tabular}

Ket $=$ ketamine medet = medetomidine; $\mathrm{pCO}_{2},=$ carbon dioxide partial pressure $;+$ air = breathing room air $;+$ oxygen = breathing oxygen; $\mathrm{pO}_{2},=$ oxygen partial pressure; $\mathrm{BE}=$ base excess; $\mathrm{HCO}_{3}=$ bicarbonate; Temp = body temperature; ${ }^{1}=1$ st sample; ${ }^{2}=2$ nd sample from same animal at end of procedure; ${ }^{\mathrm{a}-\mathrm{a}^{\prime}, \mathrm{b}-\mathrm{b}^{\prime}, \mathrm{c}^{-\mathrm{c}^{\prime}}, \mathrm{d}-\mathrm{d}^{\prime}}=\mathrm{statistically}$ significant difference $(P<0.05){ }^{\mathrm{e}}=$ excluding duplicates from means.

was the result of peripheral vasoconstriction, a direct effect of medetomidine (a $\alpha_{2}$-agonist) on the peripheral blood vessels ${ }^{20}$. Although the hypertension after $\alpha_{2}$-agonist administration is reported as transient, the combined administration with ketamine may increase the period of hypertension $^{11}$. In this investigation hypertension was also observed in the cheetahs anaesthetised with ketamine/ midazolam that would indicate that medetomidine is not the only contributor towards the high blood pressure. Other factors that may contribute towards high blood pressure are hypoxia ${ }^{5}$, increased heart rate ${ }^{18}$, and kidney disease ${ }^{6}$. Ketamine is known to increase HR and blood pressure in humans ${ }^{18}$. Hypoxia $\left(\mathrm{PO}_{2}\right.$ with values of $8.8 \pm 1.1$ and $9.8 \pm 1.1 \mathrm{kPa}$, Table 2) was observed in cheetahs breathing air during this investigation.

Increased susceptibility to kidney injury occurs in humans with chronic kidney disease during acute severe elevations in blood pressure ${ }^{1}$. In dogs prolonged high blood pressure may also increase renal injury ${ }^{4}$. Kidney disease is known to occur in captive cheetahs ${ }^{16}$ and therefore the possibility should be considered that the administration of drugs that decrease renal perfusion and increase blood pressure could increase renal morbidity during prolonged anaesthesia in animals with pre-existing renal disease.

The clinical significance of high blood pressure in immobilised cheetahs at this stage is not clear but caution should therefore be exercised when administering drugs such as medetomidine or ketamine to cheetahs with possible sub-clinical renal disease. Consideration should also be given to the possibility to antagonise medetomidine as soon as possible when anaesthesia is no longer required, or during prolonged procedures with inhalation anaesthesia to limit the period of peripheral vasoconstriction. The implication is that higher concentrations of inhalation agent will be required for maintenance, and that increased vigilance in monitoring the anaesthetic depth will be necessary when working with potentially dangerous animals.

Of interest to note was that the pressures obtained with the cuff (24.7/14.5 (18.2) kPa) were statistically significant less than the value obtained with direct arterial blood pressure measurement (33.1/21.7 $(25.0) \mathrm{kPa}$ ) in the Z/DET treatment group (Table 1). The cuff width was within the prescribed 0.55 of limb circumference ${ }^{7}$ and therefore could not be the cause of low pressure recordings with the cuff.

A significant difference $(P<0.003)$ in heart rate was observed between the K/DET $69 \pm 13.2$ beats/min compared with $97 \pm 22.6$ in the K/MID group (Table 1). The difference in HR may be explained with the presence of medetomidine. Medetomidine decreases HR and increases peripheral vascular resistance ${ }^{20}$ as compared with either midazolam or zolazepam (component of Zoletil) that has minimal effect on heart rate and peripheral vascular resistance ${ }^{10}$.

Hypoxia was observed in cheetahs breathing air (Table 2). The hypoxia was probably the result of ventilatory depression induced by the anaesthetic drugs. The statistically significant lower ventilation rate observed in the K/MID was not unexpected as midazolam is known in humans ${ }^{18}$ and goats ${ }^{21}$ to result in ventilatory depression. Breathing oxygen when connected to the anaesthetic machine resulted in a statistically significant increase in the $\mathrm{PO}_{2}$, oxyhaemoglobin saturation, and $\mathrm{PCO}_{2}$. The increase in $\mathrm{PCO}_{2}$ is probably the result of loss of the hypoxic ventilatory drive resulting in a decrease in minute ventilation. The metabolic acidoses present in most animals was probably the result of muscle exertion associated with herding them into a confined space and efforts from the cheetahs to escape. The 2 lowest values for BE $(-12.9$ and -17.8$)$ were from animals from De Wild and AfriCat and the influence of either of the techniques used during immobilisation could be implicated.

Delayed recovery associated with prolonged sedation was observed in animals immobilised with midazolam, medetomidine and ketamine. Ketamine is metabolised in the liver and excreted through the 
kidneys. The principal metabolite of ketamine (as a glucoronide) is active with an increased duration of action ${ }^{8}$. Clinically there was no evidence of disease in these animals before immobilisation with reference to appetite and habitus although the delayed recovery that was observed may indicate reduced renal function. Attempts to evaluate kidney function in cheetahs at De Wildt failed due to a poor correlation between routine kidney function tests such as blood urea nitrogen and creatinine excretion and chronic kidney disease (L. Venter, Faculty of Veterinary Science, University of Pretoria, pers. comm., 2006). The presence of sub-clinical renal disease could thus not be excluded, and may have resulted in delayed renal excretion of ketamine. The cheetah that died from aspiration was immobilised with midazolam and ketamine. Prolonged action after midazolam was also reported in humans in the presence of renal or liver malfunction ${ }^{17}$. Necropsy examination of the cheetah indicated foreign body aspiration and asphyxia from a commercial dog food meal.

In conclusion, the anaesthetic combination did not influence induction time or arterial blood pressure statistically significantly $(P>0.05)$. Hypertension was observed in all treatment groups. Heart rate was statistically significantly $(P<0.05)$ lower in the K/DET group compared with the K/MID group, and ventilation rate was statistically significantly $(P<0.05)$ lower in the K/MID group compared to the K/DET group. A metabolic acidosis, hypoxia (when breathing air) and possible hypertension were observed during anaesthesia. Oxygen administration increased $\mathrm{PO}_{2}$ and resulted in hypercapnoea during immobilisation.

\section{ACKNOWLEDGEMENTS}

The management of De Wildt Cheetah Centre and AfriCat are thanked for their cooperation in making this investigation possible. Mr M. Pieterse from Calicom Trading is thanked for his assistance during processing the blood-gas samples, lending the Osmetech analyser, and donating the Osmotech blood-gas analysis kits used during this investigation.

\section{REFERENCES}

1. Bidani A K, Griffin K A 2004 Pathophysiology of hypertensive renal damage. Implications for therapy. Hypertension 44: 595-601

2. Deem S L, Ko J C, Citino S B 1998 Anesthetic and cardiorespiratory effects of tiletaminezolazepam-medetomidine in cheetahs. Journal of the American Veterinary Medical Association 213: 1022-1026

3. Farver T B, Haskins S C, Patz J D 1986 Cardiopulmonary effects of acepromazine and the subsequent administration of ketamine in the dog. American Journal of Veterinary Research 47: 631-635

4. Finco D R 2004 Association of systemic hypertension with renal injury in dogs with induced renal failure. Journal of Veterinary Internal Medicine 18: 289-294

5. Fletcher E C 2000 Effect of episodic hypoxia on sympathetic activity and blood pressure. Respiratory Physiology 119: 189-197

6. Garovic V, Textor S C 2005 Renovascular hypertension: current concepts. Seminars in Nephrology 25: 261-271

7. Grosenbaugh DA, Muir WW III. 1998 Accuracy of noninvasive oxyhemoglobin saturation, end-tidal carbon dioxide concentration, and blood pressure monitoring during experimentally induced hypoxemia, hypotension, or hypertension in anesthetized dogs. American Journal of Veterinary Research 59: 205-212

8. Harrison N L, Sear J W 2004 Intravenous anesthetics. In Evers A S, Maze M (eds) Anesthetic pharmacology: physiologic principles and clinical practice. Churchill Livingstone Philadelphia: 395-416

9. Holmes R G, Ngethe S 1973 Restraint of captive and wild lion (Panthera leo), leopard (Panthera pardus) and cheetah (Acinonyx jubatus). Veterinary Record 92: 290-291

10. Jones D J, Stehling L C, Zauder H L 1979 Cardiovascular responses to diazepam and midazolam maleate in the dog. Anesthesiology 51: 430-434

11. Larsen R S, Loomis M R, Kelly B T, Sladky
K K, Stoskopf M K, Horne W A 2002 Cardiorespiratory effects of medetomidinebutorphanol, medetomidine-butorphanoldiazepam, and medetomidine-butorphanol-ketamine in captive red wolves (Canis rufus). Journal of Zoo and Wildlife Medicine 33: 101-107

12. Lewandowski A H, Bonar C J, Evans S E 2002 Tiletamine-zolazepam, ketamine, and xylazine anesthesia of captive cheetah (Acinonyx jubatus). Journal of Zoo and Wildlife Medicine 33: 332-336

13. Miyazaki Y, Adachi T, Kurata J, Utsumi J, Shichino T, Segawa H 1999 Dexmedetomidine reduces seizure threshold during enflurane anaesthesia in cats. British Journal of Anaesthesia 82: 935-937

14. Littman M P, Fox P R 1999 Systemic hypertension: recognition and treatment. In Fox, Sisson, Moïse (eds). Textbook of canine and feline cardiology. Principles and clinical practice (2nd edn). W B Saunders, Philadelphia: 795-813

15. McKenzie A A, Burroughs R E J 1993 Chemical capture of carnivores. In McKenzie A.A (ed.) The capture and care manual. Wildlife Decision Support Services, Pretoria: 224254

16. Munson L, Nesbit J W, Meltzer D G A, Colly L P, Bolton L, Kriek N P J 1999 Diseases of captive cheetahs (Asinonyx jubatus) in South Africa: a 20-year retrospective survey. Journal of Zoo and Wildlife Medicine 30: 342-347.

17. Nordt S P, Clark R F 1997 Midazolam: a review of therapeutic uses and toxicity Journal of Emergency Medicine 15: 357-365

18. Reves J G, Glass P S A, Lubarsky D A 2000 Nonbarbiturate intravenous anesthetics. In Miller E D (ed.) Anesthesia Vol. 1 (5th edn) Churchill Livingstone, New York: 228-272

19. Saleh N, Aoki M, Shimada T, Akiyoshi H Hassanin A, Ohashi F 2005 Renal effects of medetomidine in isoflurane-anesthetized dogs with special reference to its diuretic action. Journal of Veterinary Medical Science 67: 461-465

20. Sinclair M D 2003 A review of the physiological effects of $\alpha_{2}$-agonists related to the clinical use of medetomidine in small animal practice. Canadian Veterinary Journal 44: 885-897

21. Stegmann G F 1999 Observations on some cardiopulmonary effects of midazolam, xylazine and a midazolam/ketamine combination in the goat. Journal of the South African Veterinary Association 70: 122-126 